ORIGINAL ARTICLE

\title{
The effect of succinic acid monoethyl ester on plasma and tissue glycoproteins in streptozotocin-nicotinamide induced diabetic rats
}

\author{
Leelavinothan Pari, Ramalingam Saravanan \\ Department of Biochemistry and Biotechnology, Faculty of Science, Annamalai University, Annamalai Nagar, \\ Tamil Nadu-608 002, India.
}

Received $28^{\text {th }}$ July 2006.

Revised $18^{\text {th }}$ August 2006.

Published online $22^{\text {nd }}$ October 2006.

\begin{abstract}
Summary
Succinic acid monoethyl ester (EMS) was recently proposed as an insulinotropic agent for the treatment of non-insulin dependent diabetes mellitus. The present study investigated the effect of EMS and Metformin on dearrangement in glycoprotein levels in the streptozotocin-nicotinamide induced type 2 diabeteic model. Succinic acid monoethyl ester was administered intraperitoneally for 30 days to normal and diabetic rats. The effect of EMS on glucose, insulin, and plasma and tissue glycoproteins were studied. The effect of EMS was compared with Metformin, a reference drug. The levels of glucose, glycosylated haemoglobin and plasma glycoproteins containing hexose, hexosamine and fucose were increased significantly whereas the level of plasma insulin and haemoglobin were decreased significantly in diabetic rats. There was a significant decrease in the level of sialic acid and elevated levels of hexose, hexosamine and fucose in the liver and kidney of streptozotocin-nicotinamide diabetic rats. Administration of EMS to diabetic rats was followed by a decreased level of glucose, glycosylated haemoglobin and plasma glycoproteins. The levels of plasma insulin, haemoglobin and tissue sialic acid were increased whereas the levels of tissue hexose, hexosamine and fucose were near normal. The present study indicates that the EMS possesses a significantly beneficial effect on the glycoprotein moiety in addition to its antidiabetic effect.
\end{abstract}

Keywords: succinic acid monoethyl ester - nicotinamide - streptozotocin - glycoprotein components

\section{INTRODUCTION}

Type 2 diabetes mellitus typically involves an abnormal beta-cell function that results in relative

L. Pari, Department of Biochemistry and Biotechnology, Faculty of Science, Annamalai University, Annamalai Nagar-608 002, Tamil Nadu, India

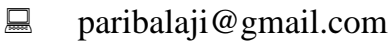

$$
\begin{aligned}
& \text { 용 + }+914144238343 \\
& \text { 自 } \quad+914144238145
\end{aligned}
$$

insulin deficiency; insulin resistance accompanied by decreased glucose transport into muscle and fat cells, and increased hepatic glucose output. All of these contribute to hyperglycaemia, resulting in the impairment of the metabolism of glucose, lipids, proteins and glycoproteins (Hawan et al. 1996). The level of different types of serum glycoproteins are maintained within a narrow range in health (Sharma and Sur 1967), but is elevated in many pathological conditions, cardiovascular disease (Tandon et al. 1983), diabetes mellitus (Anand et al. 1985). Defects in insulin secretion and insulin action are universally present in type 1 diabetes, and also type 2 diabetes, in both human patients 
and animal models. Glycoproteins are carbohydrate linked protein macromolecules found in the cell surface, which is the principal component of animal cells. Abnormal levels of glycoproteins are important in the pathogenesis of liver and kidney diseases in diabetes.

Glycoproteins are rich in extra cellular matrix and they contribute a major source to the structure of the matrix (Begum et al. 1978). It is well documented that the oligosaccharide moieties of glycoproteins: hexose, hexosamine, fucose and sialic acid have an important role in protein stability, function, and turnover (Wiese et al. 1997). In the diabetic state, glucose is utilized by the insulin independent pathways leading to the synthesis of glycoproteins, and even a mild deficiency of insulin influences the thickening of the basement membrane (Konukoglu et al. 1999). The raised levels of glycoproteins in diabetics may also be a predictor of angiopathic complications (Konukoglu et al. 1999). The therapy of non-insulin dependent diabetes mellitus presently relies upon compounds from a number of chemical classes: sulfonylureas, non-sulfonylureas and biguanides etc. A wide variety of structurally distinct molecules stimulate insulin secretion from pancreatic â cells by different mechanisms of action.

Esters of succinic acid are new potent insulin secretagogues (Fahien et al.1988, MacDonald and Fahien 1988, Picton et al. 2001) and have been proposed as a novel antidiabetic agent for type 2 diabetes. It has been previously shown that succinic acid ester can be taken up and metabolized by pancreatic â cells, leading to increased pro-insulin biosynthesis (Alarcon and Wicksteed 2002), insulin secretion and lower blood glucose (Zawalich and Zawalich 1992, GarciaMartinez et al. 1998). The possible mechanism of action of EMS could be correlated with the reminiscent effect of the hypoglycaemic sulphonylureas that promote insulin secretion by closure of $\mathrm{K}^{+}$-ATP channels, membrane depolarization and stimulation of $\mathrm{Ca}^{2+}$ influx - an initial key step in insulin secretion (Fahien et al.1988, MacDonald and Fahien 1988). These esters also protect pancreatic islets in vivo and in vitro against diabetogenic agents streptozotocin (Akkan and Malaisse 1993), interleukin 1â ( (Eizirik et al. 1994), and nitric oxide donors (Eizirik et al. 1996). Previously we had reported that EMS has a plasma glucose lowering effect in experimental type 2 diabetes (Pari and Saravanan 2005).

In non-insulin-dependent or type- 2 diabetes mellitus, oral hypoglycaemic agents are used to stimulate the pancreatic beta cells to secrete insulin and/or increase the sensitivity of peripheral insulin receptors to the action of endogenous insulin (Elson and Meredith 1998, Reusch 1998, Lebovitz 2001). The last few years have witnessed the introduction of a number of new oral agents for the treatment of type 2 diabetes with the hope of achieving better glycemic control. Metformin is a biguanide, which has been in clinical use for the treatment of type 2 diabetes for over 40 years. Metformin enhances the sensitivity of both hepatic and peripheral tissues to insulin. The drug also inhibits gluconeogenesis in the liver.

To our knowledge, no other biochemical investigations had been carried out on the effect of succinic acid monoethyl ester in streptozotocinnicotinamide diabetic rats on glycoproteins status, so the present investigation was carried out to study the effect of a nonglucidic nutrient such as EMS on plasma and tissue glycoproteins.in streptozotocinnicotinamide diabetic rats.

\section{MATERIALS AND METHODS}

\section{Drug and Chemicals}

Succinic acid monoethyl ester (Fig. 1), and all other biochemicals and chemicals used in this experiment were purchased from Sigma, USA. The chemicals were of analytical grade.<smiles>CCOC(=O)CCCC(=O)O</smiles>

Fig.1. Succinic acid monoethyl ester

Animals

Male albino Wistar strain rats $(200-220 \mathrm{~g}$ b.w. obtained from Central Animal House, Rajah Muthiah Medical College, Annamalai University were used in the present study. The rats were fed on pellet diet (Hindustan Lever Limited, Mumbai, India) and water ad libitum. The rats used in the present study were maintained in accordance with the guidelines of the National Institute of Nutrition, Indian Council of Medical Research, Hyderabad, India and the study approved by the ethical committee (Vide. No: 285, 2005), Annamalai University.

Experimental Induction of Type 2 Diabetes in Rats Non-Insulin dependent diabetes mellitus (NIDDM) was induced in rats fasted overnight by a single intraperitonial injection of $45 \mathrm{mg} / \mathrm{kg}$ streptozotocin, $15 \mathrm{~min}$ after the i.p. administration of $110 \mathrm{mg} / \mathrm{kg}$ b.w. of nicotinamide. Streptozotocin (STZ) was dissolved in citrate buffer $(\mathrm{pH} 4.5)$ and nicotinamide was dissolved in normal saline. The elevated glucose levels in plasma determined at 
$72 \mathrm{~h}$, and then on day 7 after injection, confirmed hyperglycaemia. The rats found with permanent NIDDM were used for the study (Masiello et al. 1998).

\section{Experimental Procedure}

In the experiment, a total of 42 rats (36 surviving diabetic rats, and 6 control rats) were used. The rats were divided into seven groups of six rats each.

Group I were control rats (vehicle treated). Group II were normal rats administered intraperitoneally with EMS $8 \mu \mathrm{mol} / \mathrm{g}$ bw for 30 days. Group III were diabetic control rats, and Group IV diabetic rats administered intraperitoneally with EMS $2 \mu \mathrm{mol} / \mathrm{g}$ bw for 30 days. Group V were diabetic rats administered intraperitoneally with EMS $4 \mu \mathrm{mol} / \mathrm{g}$ bw for 30 days, and GroupVI were diabetic rats administered intraperitoneally with EMS $8 \mu \mathrm{mol} / \mathrm{g}$ bw for 30 days (Pari and Saravanan 2005). Group VII were diabetic rats given Metformin $25 \mathrm{mg} / \mathrm{kg}$ bw/day in $1 \mathrm{ml}$ of saline for 30 days (Yanardag et al. 2005).

At the end of the experimental period, the rats were deprived of food overnight and blood was collected in a tube containing potassium oxalate and sodium fluoride for the estimation of plasma glucose, haemoglobin and glycosylated haemoglobin. Plasma was separated for the assay of insulin. Liver and kidney were dissected out, washed in ice-cold saline, patted dry and weighed.

\section{Analytical Methods}

Determination of plasma glucose and insulin

Plasma glucose was estimated colorimetrically using commercial diagnostic kits (Sigma Diagnostics (I) Pvt Ltd., Baroda, India) (Trinder 1969). Plasma insulin was assayed using an enzyme linked immunosorbent assay (ELISA) kit (Roche Diagnostics, Germany).

\section{Determination of haemoglobin and glycosylated haemoglobin levels}

The level of haemoglobin was estimated by using the cyanmethaemoglobin method described by Drabkin and Austin (1932). The glycosylated haemoglobin level was estimated according to the method of Sudhakar Nayak and Pattabiraman (1981) with modifications according to Bannon (1982).

\section{Determination of glycoproteins levels}

For the estimation of glycoproteins, the tissues were defatted by the method of Folch et al. (1957) and the defatted tissues were treated with $0.1 \mathrm{~N}$ $\mathrm{H}_{2} \mathrm{SO}_{4}$, hydrolysed at $80{ }^{\circ} \mathrm{C}$ and aliquot was used for sialic acid estimation. To the remaining solution, $0.1 \mathrm{~N} \mathrm{NaOH}$ was added. The aliquots were used for fucose, hexose, and hexosamine estimation. Hexose was estimated by the method described by Niebes (1972). The reaction mixture contained $0.5 \mathrm{ml}$ of aliquot/ plasma, $0.5 \mathrm{ml}$ of $5 \%$ phenol and $2.5 \mathrm{ml}$ of conc. $\mathrm{H}_{2} \mathrm{SO}_{4}$ and boiled for 20 min and absorbance was read at $490 \mathrm{~nm}$.

Hexosamine was estimated by the method of Elson and Morgan (1933) with slight modifications by Niebes (1972). Briefly, the reaction mixture contained $0.5 \mathrm{ml}$ plasma/ $1.0 \mathrm{ml}$ aliquot, and $2.5 \mathrm{ml}$ of $3 \mathrm{~N} \mathrm{HCl}$. It was boiled over $6 \mathrm{~h}$ and neutralized with $6 \mathrm{~N} \mathrm{NaOH}$. To $0.8 \mathrm{ml}$ of the neutralized sample was added $0.6 \mathrm{ml}$ of acetyl acetone reagent and it was boiled for $30 \mathrm{~min}$. The mixture was treated with $2.0 \mathrm{ml}$ of Ehrlich's reagent. The colour developed was read at $540 \mathrm{~nm}$ colorimetrically.

Sialic acid and fucose were determined by the method of Warren (1959), Dische and Shettles (1948). In brief, $0.5 \mathrm{ml}$ of aliquot/ plasma, was treated with $0.5 \mathrm{ml}$ of water and $0.25 \mathrm{ml}$ of periodic acid, and incubated at $37{ }^{\circ} \mathrm{C}$ for $30 \mathrm{~min} .0 .2 \mathrm{ml}$ of sodium meta arsenate and $2.0 \mathrm{ml}$ of thiobarbituric acid were added to the reaction mixture which was heated for 6 min. $5.0 \mathrm{ml}$ of acidified butanol was then added. The absorbance was read at $540 \mathrm{~nm}$.

For fucose estimation, $0.5 \mathrm{ml}$ of aliquot/ plasma were treated with $4.5 \mathrm{ml}$ of $\mathrm{H}_{2} \mathrm{SO}_{4}$ and boiled for $3 \mathrm{~min}$. $0.1 \mathrm{ml}$ of cysteine hydrochloride reagent was then added. After $75 \mathrm{~min}$ in the dark, the absorbance was read at 393 and $430 \mathrm{~nm}$.

\section{Statistical analysis}

The data for various biochemical parameters were analyzed using analysis of variance (ANOVA) and the group means were compared by Duncan's Multiple Range Test (DMRT). Values were considered statistically significant when $\mathrm{P}<0.05$. (Duncan 1957).

\section{RESULTS}

Plasma glucose and insulin levels

Fig. 2 demonstrates the levels of plasma glucose and insulin in control and experimental animals. In diabetic rats the level of plasma glucose was significantly increased whereas the plasma insulin was significantly decreased. The administration of EMS significantly reversed the changes in a dose dependent manner. EMS at a dose of $8 \mu \mathrm{mol} / \mathrm{g}$ bw showed a highly significant effect compared to 2 and $4 \mu \mathrm{mol} / \mathrm{g}$ bw. Administration of EMS was compared with metformin, a reference drug. The effect of EMS at a dose $8 \mu \mathrm{mol} / \mathrm{g}$ bw was used for further biochemical analysis.

Haemoglobin and glycosylated haemoglobin levels Fig. 3 shows the levels of haemoglobin and glycosylated haemoglobin in the blood of control and experimental rats. The diabetic rats showed a significant decrease in the level of total haemoglobin and a significant increase in the level 
of glycosylated haemoglobin. The administration of EMS and metformin to diabetic rats reversed the changes in total haemoglobin and glycosylated haemoglobin.

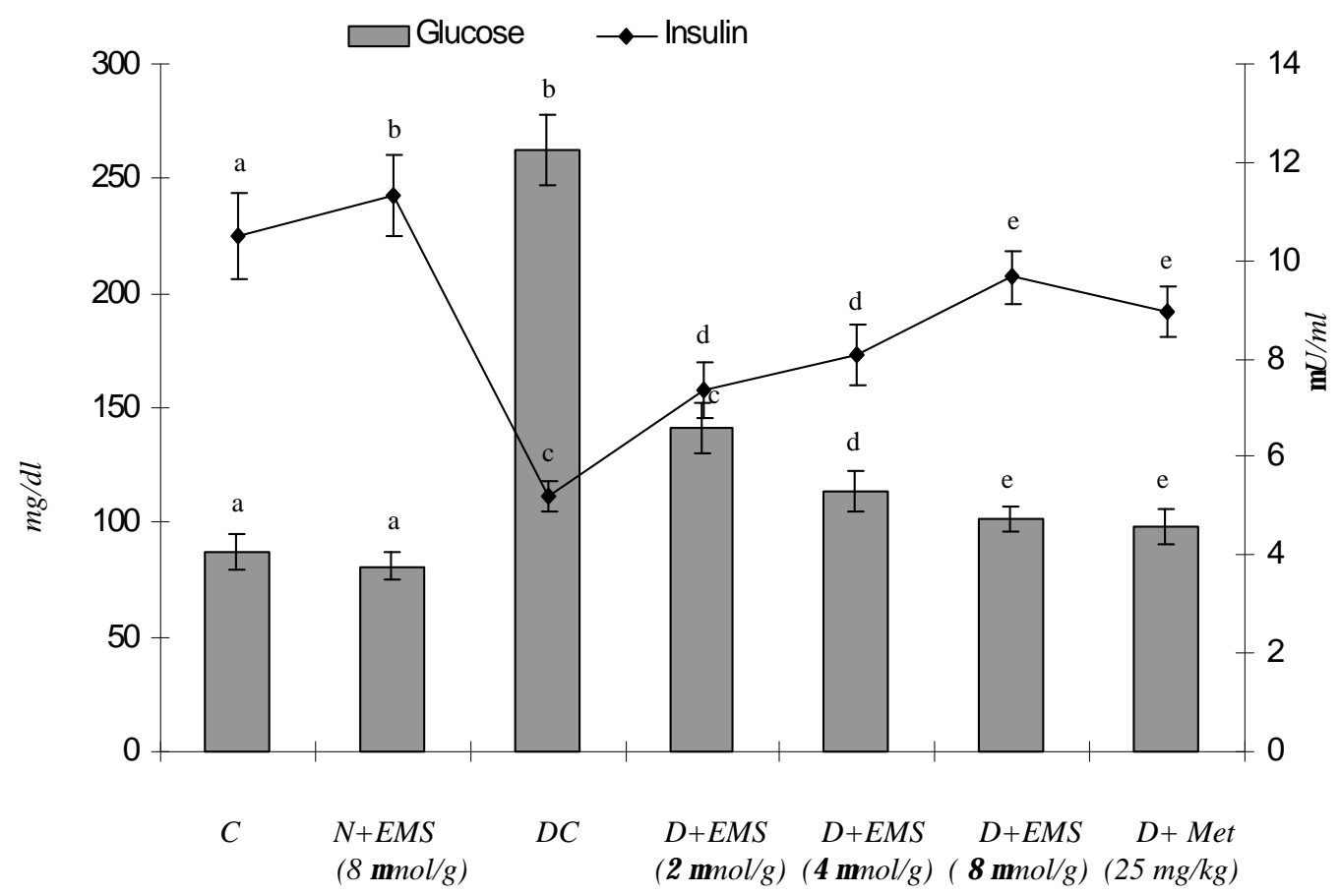

Fig. 2. Changes in the levels of plasma glucose and insulin in control and experimental animals. C, control; N, normal; DC, diabetic control; EMS, succinic acid monoethyl ester; MET, Metformin.Values are given as mean \pm S.D for 6 rats in each group. Values not sharing a common superscript letter differ significantly at $\mathrm{p}<0.05$ (DMRT).

Effect of EMS on plasma and tissue glycoproteins Fig. 4 shows the changes in the level of plasma glycoproteins of control and experimental rats. There was a significant increase of plasma glycoproteins in diabetic rats. Administration of EMS and Metformin significantly decreased the level of plasma glycoproteins.

The levels of liver and kidney glycoprotein of control and experimental rats are shown in Figs. 5-8. The levels of glycoprotens containing hexose, hexosamine and fucose were significantly increased whereas the level of sialic acid was significantly decreased in diabetic rats. Administration of EMS and metformin significantly reversed these changes in the glycoproteins levels in the liver and kidney of diabetic rats. The effect of EMS was compared with metformin.

\section{DISCUSSION}

Diabetes mellitus is a heterogeneous endocrine disorder in which hyperglycaemia is the unifying feature and, as knowledge of the heterogeneity of this disorder increases, more appropriate therapies are required (Bailey and Flalt 1986). The esters of selected carboxylic metabolites, which are mediating the Krebs cycle, or their precursors such as pyruvic acid, succinic acid, and glutamic acid, are currently under investigation as potent insulinotropic tools in the treatment of non insulin dependent diabetes (Malaisse 1995). The insulinotropic capacity of succinic acid monoethyl ester was first disclosed in pancreatic islets (Malaisse 1995). The nutritional value of this ester when infused into starved rats has been recently documented (Ladriere and Malaisse 1997). In the present investigation, treatment with EMS showed significant antihyperglycaemic activity. The administration of EMS and metformin to decrease the increased blood glucose concentration to normal glycaemic concentration is an essential trigger for the liver to revert to its normal homeostasis during experimental diabetes.

It is well documented that EMS triggers a proinsulin synthesis and insulin release similar to glucose induced insulin synthesis and release (Maechler and Wollheim 2000). MacDonald and Fahien (1988) found that initiation of insulin 
release by esters of succinate by mitochondrial metabolisms is sufficient to initiate and support insulin release from $\beta$ cells (Ainscow et al. 2000). Hyperglycaemia is the clinical hallmark of poorly controlled diabetes, which is known to cause protein glycation, also known as non - enzymatic glycosylation (Zhang and Swaan 1999). It has been reported that various proteins, including haemoglobin, albumin, collagen, low-density lipoprotein, a crystalline of lens and fibronectin, undergo non enzymatic glycation in diabetes (Koyama et al. 1998, Kumar et al. 2005). In longterm diabetes, the glycosylated form of $\mathrm{Hb}$ has an altered affinity for oxygen and this may be a factor in tissue anoxia (Yiping et al. 2004, Bunn et al.
1979). Glycosylated haemoglobin is found to be significantly increased in diabetic animals and the amount of this increase is directly proportional to the fasting blood glucose level (Peters et al. 1996, Koening et al. 1978). The level of total haemoglobin is found to be decreased in the diabetic group and this may be due to the increased formation of glycosylated haemoglobin. This was well correlated with earlier studies, which reported that there was a decrease in the level of haemoglobin in experimental diabetic rats (Shirwaukar et al. 2006). The increase in the level of haemoglobin in animals given EMS may be due to the decreased level of blood glucose.

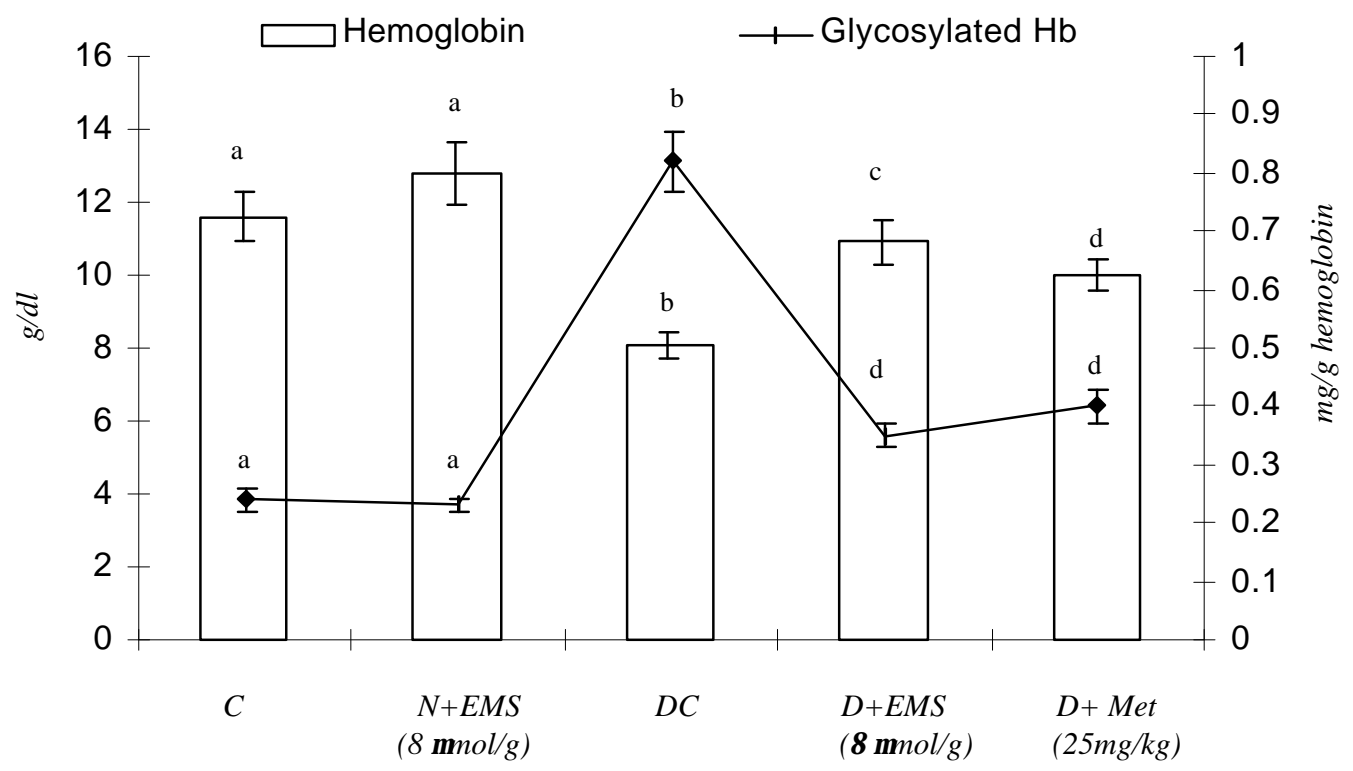

Fig. 3. Changes in the levels of plasma hemoglobin and glycosylated hemoglobin in control and experimental animals. Symbols as in Fig. 2.

Glycation is a nonenzymatic reaction of glucose and other saccharide derivatives with proteins, nucleotides and lipids (Brownlee 2001). Non-enzymatic glycation (Maillard reaction) is a complex series of reactions between reducing sugars and amino groups of proteins, which leads to browning, fluorescence and cross-linking of the proteins. The reaction is initiated by the reversible formation of a Schiff base, which undergoes a rearrangement to form a relatively stable Amadori product. The Amadori product further undergoes a series of reactions through dicarbonyl intermediates to form AGE (advanced glycation end-products). Formation of some AGEs combines both the glycation and oxidative steps in a process termed glycoxidation (Thornalley 2002). Glycation occurs inside and outside cells. Glycation of cellular proteins produces changes in structure and loss of enzymatic activity. These effects are countered by protein degradation and renewal. Glycation of the extracellular matrix produces changes in macromolecular structure affecting matrix-matrix and matrix cell interactions associated with decreased elasticity and increased fluid filtration across the arterial wall, and endothelial cell adhesion (Thornalley 2004). When the concentration of AGEs increased above a critical level, cell surface AGE receptors become activated. This is associated with increased expression of extracellular matrix proteins, vascular adhesion molecules, cytokines and growth factor. Depending on the cell type and concurrent signalling, this can be associated with chemotaxis, angiogenesis, oxidative stress, and cell proliferation or apoptosis (Thornalley 2004). These processes are thought to contribute to disease mechanisms associated with the development of diabetic complications (Vlassar and Palace 2002). 
The biochemical markers hexose, hexosamine, sialic acid, and fucose have been measured in the liver and serum because liver is responsible for the synthesis of all major proteins, which are then secreted into the blood. The present experiment attempts to extract the protective role of EMS on glycoprotein levels in control and experimental rats.

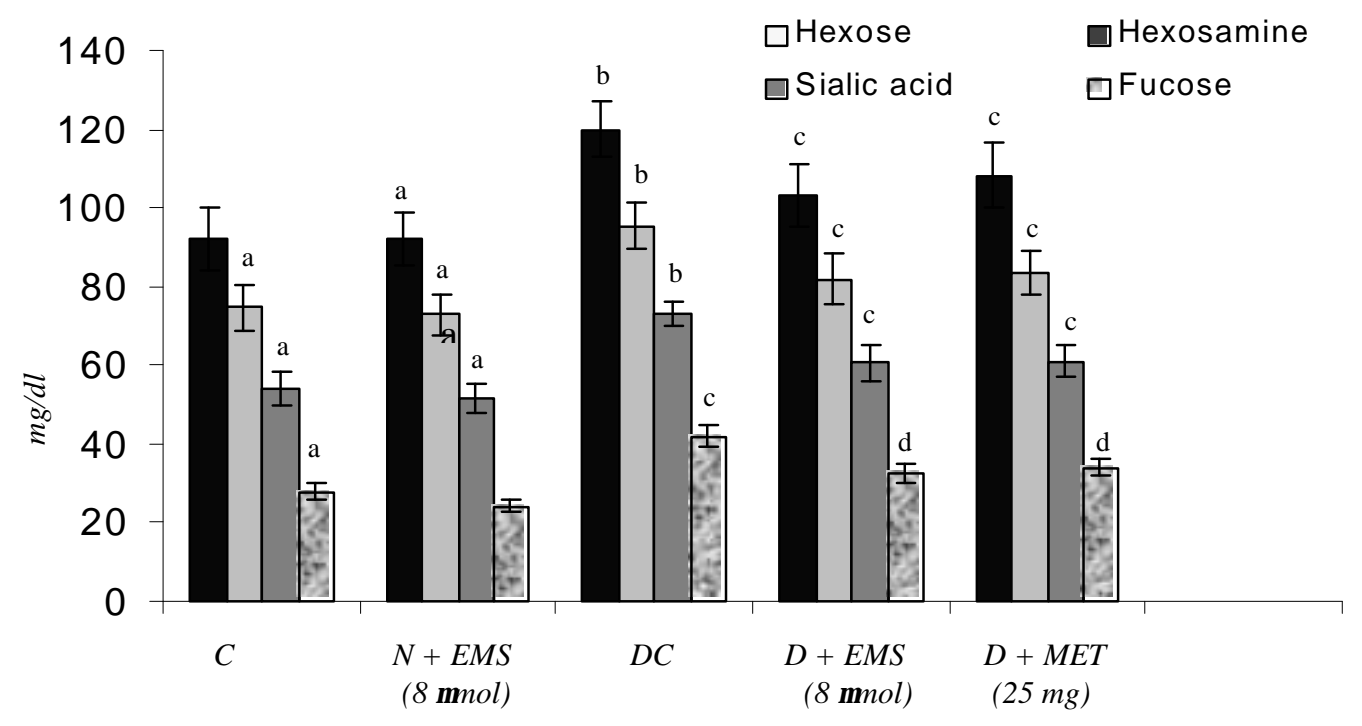

Fig. 4. Changes in the levels of plasma glycoproteins in control and experimental animals. Symbols as in Fig. 2.

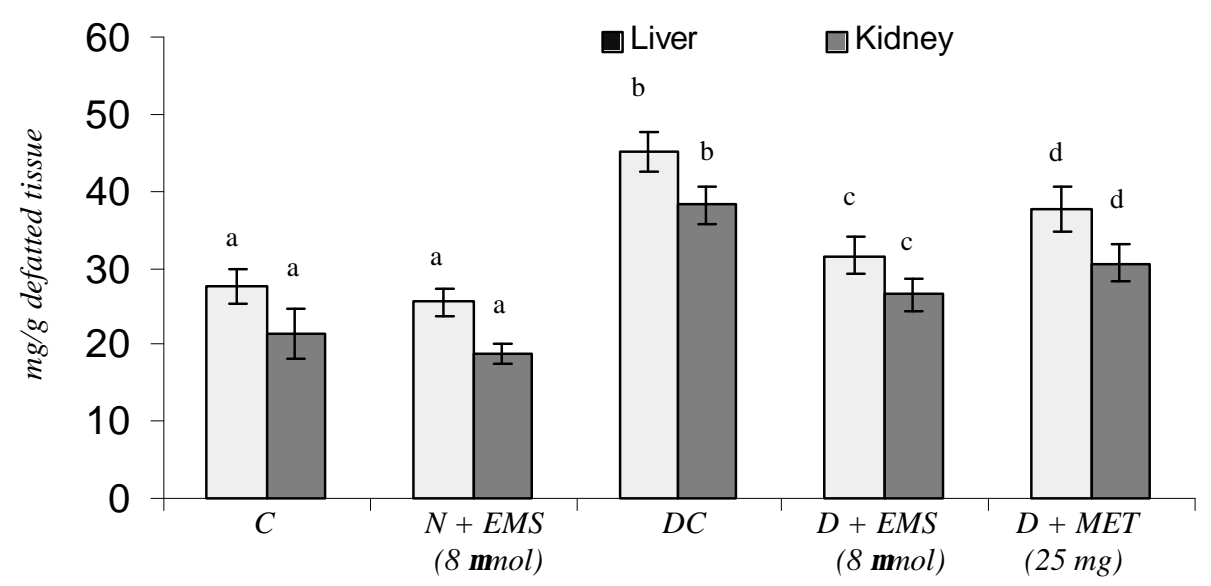

Fig. 5. Changes in the levels of tissues hexose in control and experimental animals. Symbols as in Fig. 2.

Generalized abnormalities in the metabolism of glycoproteins are observed in both naturally occurring and experimental diabetes (Mc Millan 1970, Latha and Pari 2005). Berenson et al (1972) reported that streptozotocin diabetic rats exhibited a moieties in diabetic rats may be due to insulin deficiency. The increases in plasma glycoprotein components have been reported to be associated with the severity and duration of diabetes. Glycoproteins found in a variety of tissues including the arterial wall are very similar in significant modification in the connective tissue macromolecule. The requirement of insulin for the biosynthesis of the carbohydrate moiety of mucoproteins from glucose is thus evident. Decreased incorporation of the carbohydrate structure and composition to those in circulation (Latha and Pari 2003). Therefore, vascular complications that involve complex proteincarbohydrate molecules could contribute to an increase in plasma glycoproteins. 


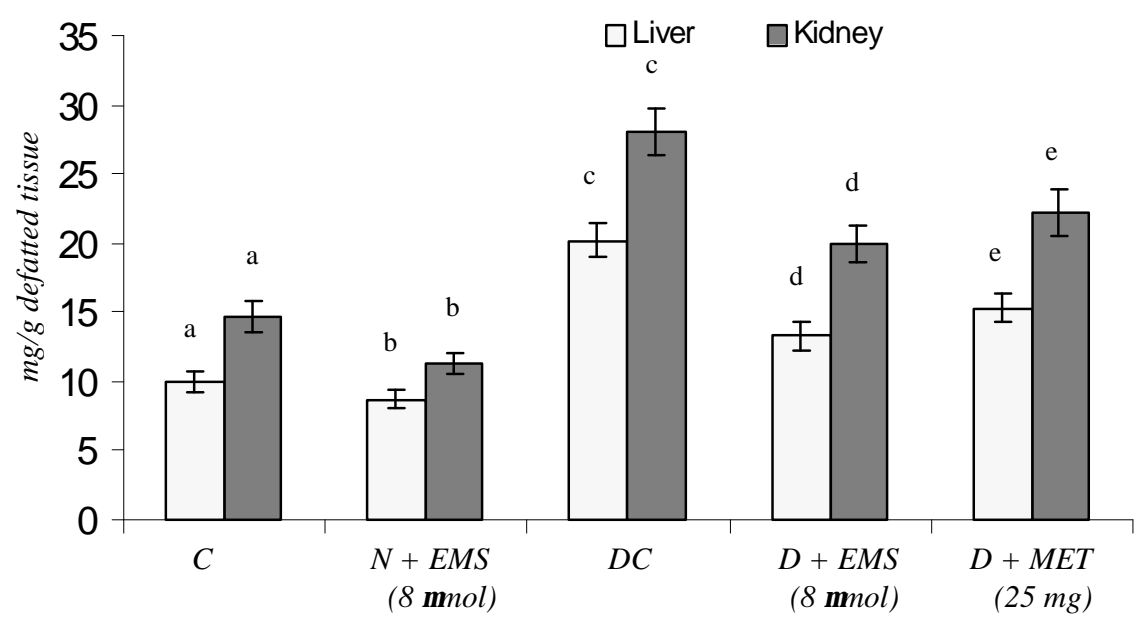

Fig. 6. Changes in the levels of tissues hexosamine in control and experimental animals. Symbols as in Fig. 2.

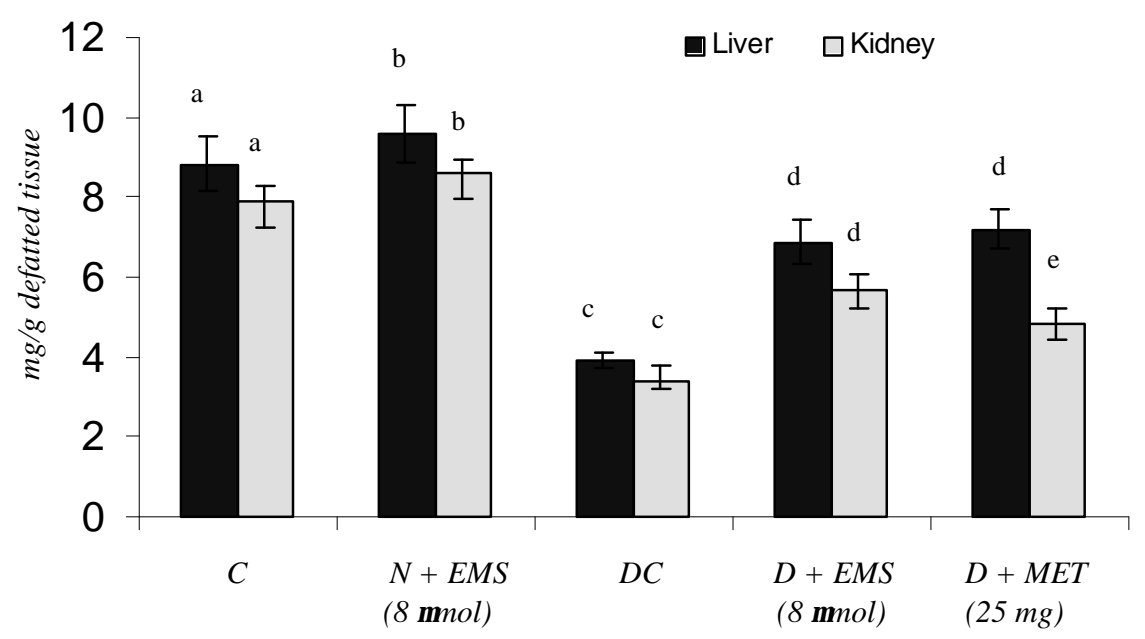

Fig. 7. Changes in the levels of tissues sialic acid in control and experimental animals. Symbols as in Fig. 2.

The biosynthesis of the carbohydrate moieties of glycoprotein forms the insulin independent pathways for the utilization of glucose-6-phosphate. But the deficiency of insulin during diabetes produces a dearrangement of glycoprotein metabolism, resulting in the thickening of basal membranes. The increased availability of glucose 1971).

An earlier study has shown that in normal circulation, fucose concentration increase as much as 8 fold in diabetes (Radhakrishnamurthy et al. 1976). In diabetes, three serum proteins (haptoglobin, á-1 acid glycoprotein and ál-antitrypsin) synthesized in the liver are mainly responsible for the increase in bound fucose levels (Mcmillan 1972, Wiese et al. 1997). The metabolism and synthesis of these proteins may be altered in diabetes leading to changes in serum in the hyperglycaemic state accelerates the synthesis of basement membrane components, i.e., glycoproteins (Radhakrishnamoorthy et al. 1973). This is due to the depressed utilization of glucose by insulin dependent pathways, thereby enhancing the formation of hexose, hexosamine and fucose for the accumulation of glycoproteins (Spiro et al. fucose content. Yorek (1993) found that fucose was significantly increased in serum from a more severely diabetic set of rats compared with the more moderately diabetic rats. Recent reports have also indicated that hepatic and serum fucosidase activities are increased in streptozotocin induced diabetic rats. Our results suggest that the increased fucosylated proteins in diabetic rats could be due to an increase in the synthesis and/or decrease in degradation of these proteins. 


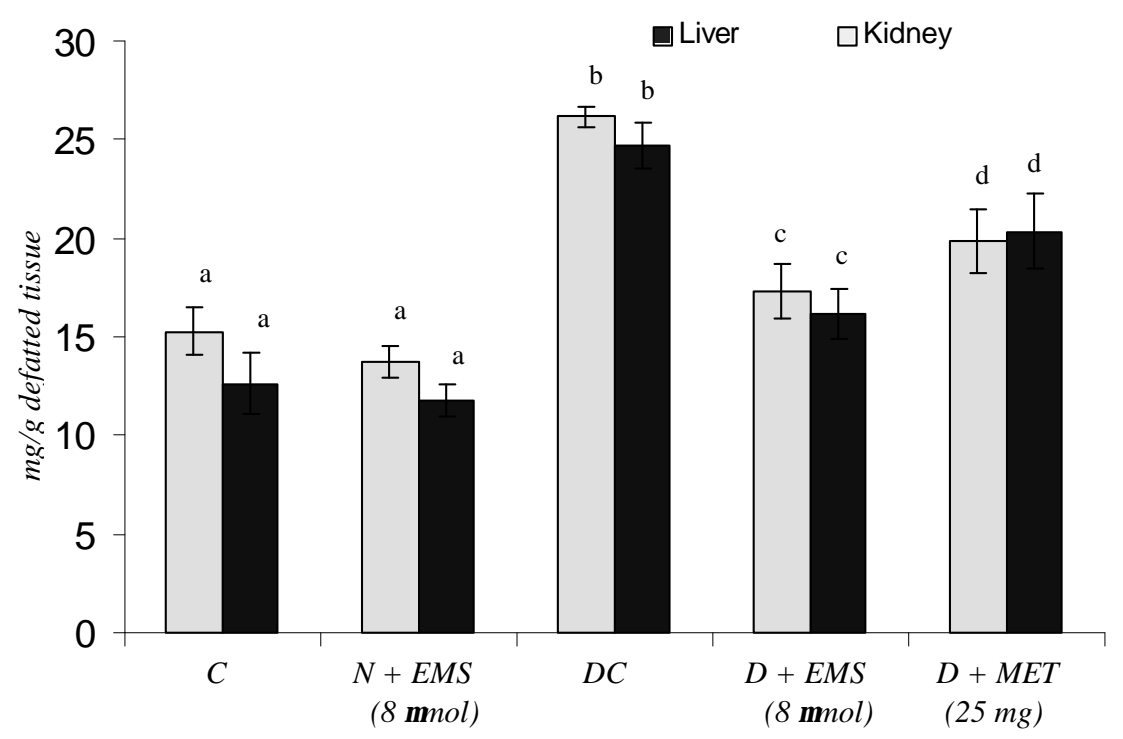

Fig. 8. Changes in the levels of tissues fucose in control and experimental animals. Symbols as in Fig. 2.

Sialic acid is an acylated derivative of neuraminic acid and exists as a terminal component of the non-reducing end of carbohydrate chains of glycoprotein in mammals. Their implications in a variety of surface-related vital cell function in numerous tissues are well documented (Patti et al. 1999). The sialic acid moiety of carbohydrate epitope is important for biological interactions including cell adhesion to selectin and lectins (Olden et al. 1982). Thus, sialic acid is an important constituent for the characteristic changes of transformed cells; the liver is the major site involved in the synthesis of sialic acid and other glycoproteins. The synthesized glycoproteins are made to circulate in blood (Patti et al. 1999). Hence, there is a pronounced increase in serum rather than in other organs. The decrease in the content of sialic acid in tissues may be due to the utilization for the synthesis of fibronectin, which contains sialic acid residues in the core structure (Schiller and Dorfman 1957). The synthesis of fibronectin was also reported to increase significantly in various tissues of diabetic patients and animals. EMS and metformin treatement of diabetic rats resulted in a significant reversal of all these changes to near normal.

\section{CONCLUSION}

Our study suggest that EMS is a structurally new insulinotropic with intense antihyperglycemic potency; further, EMS reverses the changes in the levels of the carbohydrate moieties of glycoproteins with inhibition of the excessive glycosylation, which indicates the therapeutic value of nonglucidic nutrient EMS in type 2 diabetes.

\section{REFERENCES}

Ainscow E.K., Zhao C., Rutter G.A.: Acute overexpression of lactate dehydrogenase-A perturbs beta-cell mitochondrial metabolism and insulin secretion. Diabetes 49:1149-1155, 2000.

Akkan A.G., Malaisse W.J.: Iterative pulse administration of succinic acid monomethyl ester to streptozotocin diabetic rats. Diabetes Res. 23:55-63, 1993.

Alarcon C., Wicksteed B., Prentki M, et al.: Succinate is a preferential metabolic stimuluscoupling signal for glucose-induced proinsulin biosynthesis translation. Diabetes 51:24962504, 2002.

Anand V.K., Solanki R.L., Ramdeo I.N., Tandon S.K.: A study of serum glycoproteins in diabetes mellitus. J. Assoc. Physicians India 33:273-274, 1985.

Bailey C.J., Flatt P.R.: Antidiabetic drugs need developments. Indian. J. Biotechnol. 6: 139 142, 1986.

Bannon P.: Effect of $\mathrm{pH}$ on the elimination of the labile fraction of glycosylated haemoglobin. Clin. Chem. 28:2183, 1982.

Begum N., Moses G.P.S., Shanmugasundaram K.R.: Protein bound polysaccharides in human 
and experimental diabetes. Arogya J. Health Sci. 4:140-144, 1978.

Berenson G.S., Radhakrishnamurthy, Dalferes Jr., E.R.: Connective tissue macromolecular changes in rats with experimentally induced diabetes and hyperinsulinism. Diabetes 21:733-743, 1972.

Brownlee M.: Biochemistry and molecular cell biology of diabetic complications. Nature 414: 813-820, 2001.

Bunn H.F., Shapiro R., Mc Manns M. et al.: Structural heterogenecity of human haemoglobin $A$ due to non-enzymic glycosylation. J. Biol. Chem. 254:3892-3898, 1979.

Dische Z., Shettles L.B.: A specific color reaction of methyl pentoses and a spectrophotometric micro method for their determination. J. Biol. Chem. 175:596-603, 1948.

Drabkin D.L., Austin J.M.: Spectrophotometric constants for common haemoglobin derivatives in human, dog and rabbit blood. J. Biol. Chem. 98:719-733, 1932.

Duncan B.D.: Multiple range tests for correlated and heteroscedastic means. Biometrics 13: 359-364, 1957.

Eizirik, D.L., Welsh, N., Niemann, A., et al.: Succinic acid monomethyl ester protects rat pancreatic islet secretory potential against interleukin- $1 \beta$ (IL-1 $\beta$ ) without affecting glutamate decarboxylase expression or nitric oxide production. FEBS Lett. 337:298-302, 1994.

Eizirik, D.L., Delaney, C.A., Green, M.H.L. et al.: Nitric oxide donors decrease the function and survival of human pancreatic islets. Mol. Cell. Endocrinol. 118:71-83, 1996.

Elson D.F., Meredith M.: Therapy for type-2 diabetes mellitus. Wis. Med. J. 97:49-54, 1998.

Elson L.A., Morgan W.T.J.: A colorimetric method for the determination of glucosamine and chondrosamine. Biochem. J. 27:1824-1828, 1933.

Eto K., Tsubamoto Y., Terauchi Y. et al.: Role of $\mathrm{NADH}$ shuttle system in glucose-induced activation of mitochondrial metabolism and insulin secretion. Science 283:981-985, 1999.

Fahiens L.A., MacDonald MJ., Kmiotek E.H. et al.: Regulation of insulin release by factors that also modify glutamate dehydrogenase. J. Biol. Chem. 263:13610-13614, 1988.

Folch J., Lees M., Solane S.G.H.: A simple method for isolation and purification of total lipids from animal tissues. J. Biol. Chem. 26:497$509,1957$.

GarciaMartinez J.A., VillanuevaPenacarrillo M.L., Valverde I. et al..: Potentiation of the insulinotropic and hypoglycaemic action of gliquidone by succinic acid esters. Eur. J. Pharmacol. 325:65-68, 1997.

Hawan D., Bandhu H.K, Singh B. et al.: Effect of D-400 (a herbal formulation) on the regulation of glucose metabolism in diabetic rats. Indian J. Pharmacol. 28:224-228, 1996.

Koening R.J., Peterson C.M., Jones R.: Correlation of glucose regulation and haemoglobin A1C in diabetes mellitus. N. Engl. J. Med. 295: 417-420, 1978.

Konukoglu D., Serin Ö., Akcay T., Hatemi H.: Relationship between diabetic angiopathic complications and serum total and lipid associated sialic acid concentrations. Med. Sci. Res. 27:53-55, 1999.

Koyama I., Yakushijin M., Goseki M. et al.: Partial breakdown of glycated alkaline phosphatases mediated by reactive oxygen species. Clin. Chim. Acta 275: 27-41, 1998.

Kumar P.A., Haseeb A., Suryanarayana P. et al.: Elevated expression of $\alpha \mathrm{A}-$ and $\alpha \mathrm{B}$ crystallins in streptozotocin-induced diabetic rat. Arch. Biochem. Biophys. 444:77-83, 2005.

Ladriere L., Malaisse W.J.: Nutritional value of succinic acid monoethyl ester in starvation. Ann. Nutr. Metab. 41:118-125, 1997.

Latha M., Pari L.: Preventive effects of Cassia auriculata L. flowers on brain lipid peroxidation in rats treated with streptozotocin. Mol. Cell. Biochem. 243:2328, 2003.

Latha M., Pari L.: Effect of an aqueous extract of Scoparia dulcis on plasma and tissue glycoproteins in streptozotocin induced diabetic rats. Pharmazie 60:151-154, 2005.

Lebovitz H.E.: Oral therapies for diabetic hyperglycaemia. Endocrin. Metab. Clin. North Am. 30: 909-33, 2001.

MacDonald M.J., Fahien L.A.: Glyceraldehyde phosphate and methyl esters of succinic acid. Two new potent insulin secretagogues. Diabetes 37:997-9, 1988.

Malaisse W.J.: The esters of carboxylic nutrients as insulinotropic tools in non-insulin-dependent diabetes mellitus. Gen. Pharmacol. 26: 1133-1141, 1995.

Maechler P., Wollheim C.B.: Mitochondrial signals in glucose-stimulated insulin secretion in the beta cell. J. Physiol. 529:49-56, 2000.

Masiello P., Broca C., Gross R. et al.: Experimental NIDDM: development of a new model in adult rats administered streptozotocin and nicotinamide. Diabetes 47:224-9, 1998.

McMillan D.E.: Changes in serum protein and protein bound carbohydrates in diabetes mellitus. Diabetologia 6:597-604, 1970.

McMillan D.E.: Elevation of glycoprotein fucose in diabetes mellitus. Diabetes 21:863-871, 1972. 
Niebes P.: Determination of enzymes and degradation products of glycosaminoglycans metabolism in the serum of healthy and varicose subjects. Clin. Chim. Acta. 42:399408, 1972.

Olden K., Parent J.B., White S.L.: Carbohydrate moieties of glycoproteins: a reevaluation of their functions. Biochim. Biophys. Acta 650: 209-232, 1982.

Pari L., Saravanan R.: Succinic acid monoethyl ester and metformin regulates carbohydrate metabolic enzymes and improves glycemic control in streptozotocin-nicotinamide induced type2 diabetic rats. Iran. J. Pharmacol. Ther. 4:132-137, 2005.

Patti M.E., Virkamai A., Landaker E.J. et al.: Activation of the hexosamine pathway by glucosamine in vivo induces insulin resistance of early post receptor insulin signaling events in skeletal muscles. Diabetes 48:1562-1571, 1999.

Peters A.L., Davidson M.B., Schriger D.L., Hasselblad V. A.: Clinical approach for the diagnosis of diabetes mellitus: an analysis using glycosylated haemoglobin levels. Metaanalysis research group on the diagnosis of diabetes using glycated haemoglobin levels. J. Am. Med. Assoc. 276:1246-1252, 1996.

Picton S.F., Flatt P.R., Mcclenghan N.H.: Differential acute and long-term actions of succinic acid monomethyl ester exposure on insulin secreting BRAIN- BD 11 cells. Int. J. Exp. Diabetes. Res. 2:19-27, 2001.

Radhakrishnamoorthy B., Berenson G.S.: Structure of glycopeptides from a glycoprotein from bovine aorta. J. Biol. Chem. 248:2000-2010, 1973.

Radhakrishnanamoorhy B., Berenson G.S., Pargaonkar P.S. et al.: Serum free and proteinbound sugars and cardiovascular complications in diabetes mellitus. Lab. Invest. 34:159-165, 1976.

Reusch J.E.: Focus on insulin resistance in type-2 diabetes: therapeutic implications. Diabetes Educ. 24:188-93, 1998.

Schiller S., Dorfman A.: The metabolism of mucopolysaccharides in animals. The influence of insulin. J. Biol. Chem. 227:625632, 1957.

Sharma N.C., Sur B.K.: Serum fucose and sialic acid levels in children and adults under normal and pathophysiological condition. Indian J. Med. Res. 55:380-384, 1967.

Shirwaikar A. K., Rajendran S., Barik R.: Effect of aqueous bark extract of Garaga pinnata Roxb in streptozotocin-nicotinamide induced type II diabetes mellitus. J. Ethnopharmacol. 107:285-290, 2006.

Spiro R.G., Spiro M.J.: Effect of diabetes on the biosynthesis of the renal glomerular basement membrane. Studies on the glycosyl transferase. Diabetes 20:641-648, 1971.

Sudhakar Nayak S., Pattabiraman T.N.: A new colorimetric method for the estimation of glycosylated haemoglobin. Clin. Chem. Acta. 109:267-274, 1981.

Tandon S.K., Solanki R.L., Ramdeo I.N. et al.: A study of serum glycoprotein in cardiovascular disorders. Indian J. Med. Res. 37:223-225, 1983.

Thornalley P. J.: Glycation diabetic neurpathy; characteristics, consensus causes, and therapeutic options. Int. Rev. Neurobiol. 50: 37-57, 2002.

Thornalley P. J.: Glycation and/or polyol pathway inducing complications. Encyclopedia of Endocrine Dis. 2:257-278, 2004.

Trinder P.: Determination of glucose in blood using glucose oxidase with an alternative oxygen acceptor. Ann. Clin. Biochem. 6:24-27, 1969.

Vlassara H., Palace M. R.: Diabetes and advanced glycation end products. J. Intern. Med. 251: 87-101, 2002.

Warren L.: The thiobarbituric acid assay of sialic acids. J. Biol. Chem 234:1971-1975, 1959.

Wiese T. J., Dunlap J.A., Yorek M.A.: Effect of Lfucose and L-glucose concentration on Lfucoprotein metabolism in human Hep G2 cells and changes in fucosyltransferase and $\alpha \mathrm{L}$-fucosidase activity in liver of diabetic rats. Biochim. Biophys. Acta 1:61-72, 1997.

Yanardag R., Ozsoy-Sacan O., Bolkent S. et al.: Protective effects of metformin treatment on the liver injury of streptozotocin-diabetic rats. Hum. Exp. Toxicol. 24:129-135, 2005.

Yorek M.A., Wiese T.J., Davidson E.P., et al.: Reduced motor-nerve conduction-velocity and $\mathrm{Na}^{+}-\mathrm{K}^{+}$-ATPase activity in rats maintained on L-fucose diet: reversal by myoinositol supplementation. Diabetes 42:1401-1406, 1993.

Yiping J.I.A., Ramasamy S., Wood F. et al.: Crosslinking with O-raffinose lowers oxygen affinity and stabilizes haemoglobin in a noncooperative T-state conformation. Biochem. J. 384:367-375, 2004.

Zawalich W.S., Zawalich K.C.: Biochemical mechanisms involved in monomethyl succinate-induced insulin secretion. Endocrinology 131:649-654, 1992.

Zhang E.Y., Swaan P.W.: Determination of membrane protein glycation in diabetic tissue. AAPS PharmSci. 20:1-7, 1999. 